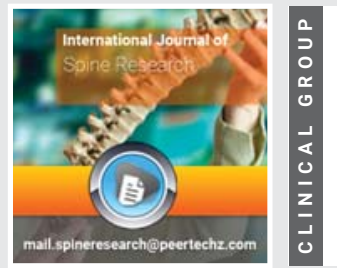

\section{Prospective evaluation of} relationship between MRI

\section{findings and ASIA score to}

predict neurological recovery

\section{in acute traumatic spinal cord injury}

\section{Roop Singh ${ }^{1 *}$, Vijay Singh Meena ${ }^{1}$, Pankaj Sharma ${ }^{1}$, Kiranpreet Kaur ${ }^{2}$ and Svareen ${ }^{3}$}

'Department of Orthopaedic Surgery, Paraplegia \& Rehabilitation, Pt. B.D. Sharma PGIMS, Rohtak-124001 (Haryana) India

${ }^{2}$ Department of Anaesthesiology and Critical Care, Pt. B.D. Sharma PGIMS, Rohtak-124001 (Haryana) India

${ }^{3}$ Baba Saheb Ambedkar Medical College, Rohini, New Delhi, India
Received: 22 February, 2019

Accepted: 04 April, 2020

Published: 06 April, 2020

*Corresponding author: Roop Singh, Department of Orthopaedic Surgery, Paraplegia and Rehabilitation, Pandit Bhagwat Dayal Sharma Post Graduate Institute of Medical Sciences (PGIMS), Rohtak, India, E-mail: drroopsingh@rediffmail.com

Keywords: MRI; Spinal cord injury; ASIA score; Neurological recovery

https://www.peertechz.com

Check for updates

\begin{abstract}
Introduction: The role of MRI in evaluating the acutely injured spine is well established and contributes to assessment of ligamentous disruption, associated disc protrusions as well as exact site of maximal canal stenosis and nature of cord injury; and neurological assessment as per ASIA score is an internationally accepted method. It is not well established the MRI at any point of time correlates with ASIA score to prognosticate neurological recovery.
\end{abstract}

Aims: The present study aimed to evaluate relationship between MRI findings and ASIA score to predict neurological deficit and recovery in acute SCI patients.

Methods: Thirty-five patients of acute spinal cord injury with mean age of $31.34 \pm 10.63$ years (range 16 to 65 years), who have been presented within 48 hours of injury were included in the study. Complete neurological (ASIA grading) and MRI examinations were done at presentation, 3 months, and 6 months to evaluate the SCI. Statistical analysis of MRI (qualitative \& quantitative) findings and clinical evaluation was done with ASIA scoring to find an agreement between MRI and neurological outcome.

Results: The statistically significant correlation was found to be with Maximum Canal Compromise (MCC) (-0.703) followed by lesion length (-0.678), Maximum Spinal Cord Compression (MSCC) (-0.661), stenosis (-0.577) and disc herniation (-0.420) to prognosticate the neural recovery as determined by ASIA score. The rest of MRI findings didn't have significant correlation with ASIA score at any point of time. However, decrease in edema significantly correlated with ASIA score at 3 and 6 months post injury. Statistically significant kappa agreement between neurological recovery diagnosed by ASIA score and MRI findings was found with MCC ( $\mathrm{k}=0.211$ ) and soft tissue injury $(\mathrm{k}=0.318)$.

Conclusions: The present study showed that significant correlation exist between MRI findings (MCC, MSCC, stenosis, and disc herniation) and ASIA score at different point of time post SCI. Furthermore, statistically significant kappa agreement between neurological recovery diagnosed by ASIA score and MRI findings (MCC and soft tissue injury) was found. We suggest that serial neurologic examination and neuroimaging complement each other in prognosticating neurological recovery after acute traumatic SCI. 


\section{Introduction}

Acute traumatic Spinal Cord Injuries (SCI) represent one of the commonest devastating injuries, more prevalent in the younger population (16-30 years) and creating physical, emotional, and economic burdens on both the individual as well as to the society. Recent demographics demonstrate a trend toward increasing average age at the time of injury and more violence-related events [1]. A Spinal Cord Injury (SCI) refers to any injury to the spinal cord that is caused by trauma instead of systemic or regional disease. Depending on the site where the spinal cord and nerve roots are damaged, the symptoms can vary widely, from pain to paralysis to incontinence [2]. Spinal cord injuries are described at various levels of "incomplete", which can vary from having no effect on the patient to a "complete" injury which means a total loss of function [35]. Several radiological investigations including radiographs (x-rays) and Computed Tomogram (CT) scans are available but advent of Magnetic Resonance Imaging (MRI) has enabled the non-invasive visualisation of the spinal cord in both diagnostic as well as in prognostic purposes. MR imaging is indicated in the setting of spinal trauma when a neurologic deficit present or when there is clinical suspicion of a soft tissue or vascular abnormality. The role of MRI in evaluating the acutely injured spine is well established and contributes to assessment of ligamentous disruption, associated disc protrusions as well as exact site of maximal canal stenosis and nature of cord injury [6-13]. Present study aimed to evaluate relationship between MRI findings and ASIA score to predict neurological recovery in acute Spinal Cord Injury (SCI) patients. We further evaluated whether there was an agreement in these two to predict neurological prognosis.

\section{Material and methods}

Approval from Institutional Review Board and Ethical Committee was taken before enrollment of patients in the study, and written informed consent was obtained from all the patients. Thirty-five patients of acute spinal cord injury with mean age of $31.34 \pm 10.63$ years (range 16 to 65 years), who have been presented within 48 hours of injury to Orthopaedics emergency department in institute within period from June 2014 to November 2016, included in present prospective study. Patients having spinal cord injury either with non-traumatic etiology or with head injury/medically unstable condition or with previous implanted metallic devices or with claustrophobia, pacemakers and cochlear implants or presenting with previous neurological deficits and gunshot wounds were excluded from the study. There was male preponderance incidence [male: female; $29(82.9 \%): 6(17.1 \%)]$. Most injuries were at the first lumbar vertebral level in 14 subjects $(40.0 \%)$ followed by second lumbar and thoracic twelfth in $5(14.3 \%)$ subjects each, while mode of injury was fall from height (34 subjects, 97.1\%) followed by road side accidents (1 subject, $2.9 \%$ ). The mean duration of time elapsed between injury and MR imaging was $18.97 \pm 4.86$ hours (range 6 to 24 hours) with maximum (30 subjects, $85.7 \%$ ), investigated between $13-24$ hours. Thorough chronological history along with complete clinical assessment (sensory score, motor score and zone of partial preservation) was done at the time of admission, on $3^{\text {rd }}$ day, on $7^{\text {th }}$ day, at 3 months and at 6 months of injury as per international guidelines [14]. Plain radiographs of the spine were done on admission to diagnose the level and calculate sagittal index, Gardener Segmental Kyphotic Deformity, and regional kyphotic deformity as described by Farcy et al [15]. MRI was done in all cases for confirmatory diagnosis within 48 hours of injury and assessment of quantitative parameters [MSCC (Maximum Spinal Cord Compression), MCC (Maximum Canal Compromise) and lesion length] as well as qualitative parameters (cord edema, hemorrhage, Soft Tissue Injury (STI), disc herniation and posterior ligament complex injury) was done by the method described by Fehlings et al [16]. Plain radiographs and MRI were repeated at 3 and 6 months. Traumatic spinal cord injury was classified into five categories (score A with complete injury of spine, score B, C, D with incomplete injury and score E with no neural deficit) on the ASIA Impairment Scale [17]. Statistical analysis of MRI (qualitative \& quantitative) findings and clinical evaluation was done with ASIA scoring to find an agreement between MRI and neurological outcome.

\section{Statistical analysis}

Normally distributed variables (means and standard deviation) were analysed using Student $\mathrm{t}$-test and repeated measure analysis of variances (ANOVA). Chi-square test, Friedman ANOVA and Cochran's Q test were employed for categorical and ordinal data. Correlation between variables was assessed by Spearman coefficient of correlation. Standard

Table 1: Distribution of subjects according to their symptomatology $(n=35)$

\begin{tabular}{|c|c|c|c|c|}
\hline Symptoms & Initial & 3 months & 6 months & Significance* \\
\hline Pain & $35(100.0 \%)$ & $13(37.1 \%)$ & $2(5.7 \%)$ & $\mathrm{p}<0.001$ \\
\hline Swelling & $35(100.0 \%)$ & $0(0.0 \%)$ & $0(0.0 \%)$ & $\mathrm{p}<0.001$ \\
\hline Deformity & $35(100.0 \%)$ & $17(48.6 \%)$ & $3(8.6 \%)$ & $\mathrm{p}<0.001$ \\
\hline Weakness UL & $2(5.7 \%)$ & $2(5.7 \%)$ & $1(2.9 \%)$ & $\mathrm{p}=0.368$ \\
\hline Weakness LL & $33(94.3 \%)$ & $25(71.4 \%)$ & $17(48.6 \%)$ & $\mathrm{p}<0.001$ \\
\hline Incontinence & $0(0.0 \%)$ & $0(0.0 \%)$ & $5(14.3 \%)$ & $\mathrm{p}=0.007$ \\
\hline Retention & $27(77.1 \%)$ & $20(57.1 \%)$ & $7(20.0 \%)$ & $\mathrm{p}<0.001$ \\
\hline
\end{tabular}

*Cochran's Q test

Table 2: Distribution of subjects according to their neurological assessment $(n=35)$

\begin{tabular}{|c|c|c|c|c|c|}
\hline Neurological assessment & Initial & 3 months & 6 months & Significance \\
\hline Decreased Muscle Tone & $33(94.3 \%)$ & $27(77.1 \%)$ & $18(51.4 \%)$ & $\mathrm{p}<0.001^{*}$ \\
\hline MIS-UL & $48.69 \pm$ & $49.57 \pm 1.80$ & $49.74 \pm$ & $\mathrm{p}=0.232^{\#}$ \\
\hline MIS-LL & $13.34 \pm$ & $30.09 \pm$ & $40.91 \pm$ & $\mathrm{p}<0.001^{\#}$ \\
\hline Voluntary Anal Contraction & $30(85.7 \%)$ & $22(62.9 \%)$ & $7(20.0 \%)$ & $\mathrm{p}<0.001^{*}$ \\
\hline SIS- Light touch & $84.29 \pm$ & $106.11 \pm$ & $110.69 \pm$ & $\mathrm{p}<0.001^{\#}$ \\
\hline SIS- Pin prick & $81.60 \pm$ & $102.17 \pm$ & $110.23 \pm$ & $\mathrm{p}<0.001^{\#}$ \\
\hline Temperature sense & $18(51.4 \%)$ & $3(8.6 \%)$ & $0(0.0 \%)$ & $\mathrm{p}<0.001^{*}$ \\
\hline Deep Anal Pressure (DAP) & $21(60.0 \%)$ & $11(31.4 \%)$ & $2(5.7 \%)$ & $\mathrm{p}<0.001^{*}$ \\
\hline Clonus (Absent) & $35(100.0 \%)$ & $35(100.0 \%)$ & $35(100.0 \%)$ & $\mathrm{p}=1.000^{*}$ \\
\hline
\end{tabular}

\begin{tabular}{l|l|l|l|l} 
Zone of partial preservation & $35(100.0 \%)$ & $35(100.0 \%)$ & $35(100.0 \%)$ & $p=1.000 *$
\end{tabular}

*Cochran's Q test, \#Repeated Measures ANOVA 
Statistical software (SPSS version 20.0) was used for statistical analysis and a p-value of $<0.05$ was considered statistically significant.

\section{Results}

\section{Clinical parameters and neurology}

Distribution of subjects according to their symptomatology is depicted in the table 1. Neurological assessment was done with different variables including muscle tone, Motor Index Score ( MIS), Voluntary Anal Contraction (VAC), Sensory Index Scoring (SIS), temperature, Deep Anal Pressure (DAP), clonus and Zone of Partial Preservation (ZPP). These all variables are tabulated at different follow up of time in table 2 .

The median neurological grade improved from score $\mathrm{C}$ to $\mathrm{D}$ in initial 3 months and score $\mathrm{D}$ to $\mathrm{E}$ in next 3 months. The neurological recovery was highly significant $(\mathrm{p}<0.001)$ by Friedman ANOVA test. At initial documentation, 20\% (7) and $5.7 \%$ (2) subjects presented with complete injury and no deficit respectively (ASIA score $\mathrm{A}$ and $\mathrm{E}$ ), whereas maximum subjects $(20,57.1 \%)$ were classified into grade $\mathrm{C}$. At the end of 6 months, maximum subjects had no deficit (18 subjects, $51.4 \%$ ).

\section{MRI parameters}

The difference in various quantitative and qualitative parameters on MRI findings observed have been tabulated in Table 3; and according to their neurological status at the time

Table 3: Qualitative and quantitative findings on MRI observed initially and at subsequent follow-ups $(n=35)$.

\begin{tabular}{|c|c|c|c|c|}
\hline Findings & Initial & 3 months & 6 months & Significance \\
\hline \multicolumn{5}{|l|}{ Qualitative Findings } \\
\hline Edema & $34(97.1 \%)$ & $27(77.1 \%)$ & $8(22.9 \%)$ & $p<0.001^{*}$ \\
\hline Hemorrhage & $10(28.6 \%)$ & $6(17.1 \%)$ & $0(0.0 \%)$ & $\mathrm{p}=0.004^{*}$ \\
\hline Cord swelling & $1(2.9 \%)$ & $1(2.9 \%)$ & $1(2.9 \%)$ & $p=1.000^{*}$ \\
\hline Soft tissue injury & $8(22.9 \%)$ & $7(20.0 \%)$ & $3(8.6 \%)$ & $p=0.015^{*}$ \\
\hline Stenosis & $19(54.3 \%)$ & $19(54.3 \%)$ & $16(45.7 \%)$ & $\mathrm{p}=0.050^{*}$ \\
\hline Disc herniation & $25(71.4 \%)$ & $23(65.7 \%)$ & $20(57.1 \%)$ & $\mathrm{p}=0.022^{*}$ \\
\hline Epidural hematoma & $0(0.0 \%)$ & $0(0.0 \%)$ & $0(0.0 \%)$ & $p=1.000^{*}$ \\
\hline Body Fracture & $34(97.1 \%)$ & $34(97.1 \%)$ & $34(97.1 \%)$ & $p=1.000 *$ \\
\hline Altered marrow signal & $35(100.0 \%)$ & $35(100.0 \%)$ & $35(100.0 \%)$ & $p=1.000^{*}$ \\
\hline Posterior element fracture & $8(22.9 \%)$ & $8(22.9 \%)$ & $8(22.9 \%)$ & $p=1.000^{*}$ \\
\hline $\begin{array}{l}\text { Posterior ligament complex } \\
\text { injury }\end{array}$ & $8(22.9 \%)$ & $8(22.9 \%)$ & $4(11.4 \%)$ & $\mathrm{p}=0.018^{*}$ \\
\hline Pre-vertebral edema & $0(0.0 \%)$ & $0(0.0 \%)$ & $0(0.0 \%)$ & $p=1.000 *$ \\
\hline Subluxation & $1(2.9 \%)$ & $0(0.0 \%)$ & $0(0.0 \%)$ & $p=0.368^{*}$ \\
\hline Spondylosis & $0(0.0 \%)$ & $0(0.0 \%)$ & $0(0.0 \%)$ & $p=1.000 *$ \\
\hline Foreign body & $0(0.0 \%)$ & $0(0.0 \%)$ & $0(0.0 \%)$ & $p=1.000^{*}$ \\
\hline \multicolumn{5}{|l|}{ Quantitative findings } \\
\hline $\begin{array}{l}\text { Maximum spinal cord } \\
\text { compression }\end{array}$ & $\begin{array}{l}57.43 \pm \\
29.05\end{array}$ & $\begin{array}{l}32.83 \pm \\
25.58\end{array}$ & $\begin{array}{c}18.57 \pm \\
17.43\end{array}$ & $\mathrm{p}<0.001^{* *}$ \\
\hline Maximal canal compromise & $\begin{array}{l}61.60 \pm \\
29.70\end{array}$ & $\begin{array}{l}37.91 \pm \\
27.63\end{array}$ & $\begin{array}{c}20.91 \pm \\
18.07\end{array}$ & $p<0.001^{\star *}$ \\
\hline Lesion length & $\begin{array}{c}10.34 \pm \\
9.31\end{array}$ & $7.30 \pm 6.96$ & $5.05 \pm 5.47$ & $p<0.001 * \star$ \\
\hline
\end{tabular}

*Cochran's Q test ** Repeated measures ANOVA.
Table 4: Comparison of initial neurological status in terms of complete and incomplete injury with qualitative and quantitative parameters.

\begin{tabular}{|c|c|c|c|c|}
\hline \multirow[b]{2}{*}{ PARAMETERS } & \multicolumn{3}{|c|}{ Severity of initial injury } & \multirow[b]{2}{*}{ Significance } \\
\hline & $\begin{array}{c}\text { Complete SCI } \\
\text { (ASIA Grade A) } \\
(n=7)\end{array}$ & $\begin{array}{l}\text { Incomplete SCI } \\
\text { (ASIA Grade } \\
\text { B,C,D) }(n=26)\end{array}$ & $\begin{array}{c}\text { No deficit } \\
\text { (ASIA Grade E) } \\
(n=2)\end{array}$ & \\
\hline \multicolumn{5}{|l|}{ QUALITATIVE } \\
\hline Edema & $7(100.0 \%)$ & $25(96.2 \%)$ & $2(100.0 \%)$ & $\mathrm{p}=0.837^{\star}$ \\
\hline Haemorrhage & $3(30 \%)$ & $7(70 \%)$ & $0(0 \%)$ & $p=0.021^{\star}$ \\
\hline Cord swelling & $0(0.0 \%)$ & $1(3.8 \%)$ & $0(0.0 \%)$ & $\mathrm{p}=0.837^{\star}$ \\
\hline Soft tissue injury & $2(28.6 \%)$ & $5(19.2 \%)$ & $1(50.0 \%)$ & $p=0.560 *$ \\
\hline Stenosis & $7(100.0 \%)$ & $12(46.2 \%)$ & $0(0.0 \%)$ & $p=0.011^{\star}$ \\
\hline Disc herniation & $7(100.0 \%)$ & $16(61.5 \%)$ & $2(100 \%)$ & $p=0.089 *$ \\
\hline Body Fracture & $7(100.0 \%)$ & $25(96.2 \%)$ & $2(100 \%)$ & $\mathrm{p}=0.837^{\star}$ \\
\hline $\begin{array}{c}\text { Posterior } \\
\text { element fracture }\end{array}$ & $3(42.9 \%)$ & $4(15.4 \%)$ & $1(50.0 \%)$ & $p=0.197$ * \\
\hline $\begin{array}{c}\text { Posterior } \\
\text { ligament } \\
\text { complex injury }\end{array}$ & $3(42.9 \%)$ & $4(15.4 \%)$ & $1(50.0 \%)$ & $p=0.197 *$ \\
\hline Subluxation & $0(0.0 \%)$ & $1(3.8 \%)$ & $0(0.0 \%)$ & $\mathrm{p}=0.837^{*}$ \\
\hline \multicolumn{5}{|l|}{ QUANTITATIVE } \\
\hline $\begin{array}{c}\text { Maximum } \\
\text { spinal cord } \\
\text { compression }\end{array}$ & $83.14 \pm 2.04$ & $54.04 \pm 27.95$ & $11.50 \pm 0.71$ & $p=0.002^{\star \star}$ \\
\hline $\begin{array}{l}\text { Maximal canal } \\
\text { compromise }\end{array}$ & $88.43 \pm 2.15$ & $58.00 \pm 28.38$ & $14.50 \pm 2.12$ & $\mathrm{p}=0.002^{\star \star}$ \\
\hline Lesion length & $19.29 \pm 7.00$ & $8.73 \pm 8.51$ & $0.00 \pm 0.00$ & $\mathrm{p}=0.005^{\star \star}$ \\
\hline
\end{tabular}

of admission in terms of severity of injury assessed by ASIA score have been represented in Table 4 .

Qualitative: There was statistically significant $(\mathrm{p}<0.001)$ improvement in neurological function of subjects who had edema initially (34 subjects) as seen on follow up visits with median ASIA score to be C initially, D at 3 months and $\mathrm{E}$ at 6 months with 7 (20.01\%) patients showed no improvement on follow up and these patients were also having intramedullary haemorrhage. There were 10 patients with initial haemorrhage. Three patients had ASIA A and 7 patients had ASIA C neurological status; and neurological improvement was noted in $6(60.0 \%)$ patients and rest of the $4(40.0 \%)$ patients showed no improvement on follow up. There was statistical difference $(p=0.014)$ in neurological outcome between patients who had haemorrhage and those not having haemorrhage. Cord swelling was observed in only single patient and it persisted throughout the final follow- up. STI was present initially in $22.9 \%$ (8) of subjects, persisted in only $8.6 \%$ (3) subjects after 6 months with statistically significant $(p=0.014)$ improvement in neurological function with median ASIA score to be $\mathrm{C}$ initially, $\mathrm{C}$ at 3 months and $\mathrm{D}$ at 6 months. There was statistically significant $(p<0.001)$ improvement in neurological function, who had stenosis initially (19 patients) with median ASIA score to be C initially, C at 3 months and D at 6 months, while $4(21.1 \%)$ out of 19 patients showed no improvement.

Quantitative: Subjects with compression of MSCC > 50\%, improved from median ASIA score from $\mathrm{C}$ to $\mathrm{C}$ at 3 months and $D$ at 6 months, while for subject's compression $\leq 50 \%$ score to be $\mathrm{D}$ initially, $\mathrm{D}$ at 3 months and $\mathrm{E}$ at 6 months with significant neurological improvement $(p<0.001)$. 
Similarly, mean MCC decreased significantly from $(61.60 \% \pm$ $29.70)$ to $(20.91 \% \pm 18.07)$, ( $p<0.001)$ at final follow up. There was improvement in neurological function of subjects who had initial MCC $\leq 50 \%$ as seen on follow up visits with median ASIA score to be D initially, $\mathrm{E}$ at 3 months and $\mathrm{E}$ at 6 months. This improvement in neurological function was found to be statistically significant $(p<0.001)$

There was significant improvement in neurological function with initial lesion length $\leq 50 \mathrm{~mm}$, reflecting median ASIA score to be $\mathrm{C}$ initially, D at 3 months and $\mathrm{E}$ at 6 months, $(p<0.001)$.

Correlation matrix of MRI findings and ASIA score (Spearman's correlation test) is shown in Table 5.

Statistically significant kappa agreement between neurological recovery diagnosed by ASIA score and MRI findings was found with maximum canal compromise $(\mathrm{k}=0.211)$ and soft tissue injury $(\mathrm{k}=0.318)$ only (Table 6$)$

\section{Discussion}

MRI is a gold standard for evaluation of SCI patients; and qualitative and quantitative parameter have been defined and evaluated in SCI. Most studies in the literature had registered the qualitative variables to examine the association between imaging parameters and neurological outcome in SCI $[5,6,9,11-$ 13,18-22]. There are only a few studies which evaluated the quantitative variables (degree of spinal canal compromise, cord compression and length of lesion) [11-13,23,24]. The present study used an objective method, which has previously been approved to be reliable, standardized and objective, to quantify MR images obtained from patients with SCI $[16,25]$.

\section{Qualitative MRI findings}

Most of the subjective changes in spinal cord are related to secondary insults following the initial trauma, but the extent of cord damage is proportionate to the initial impact force [26,27]. Even minor injuries can also cause significant cord malfunction, while there is some resistant of the cord to direct physical disruption [13]. Intramedullary haemorrhage is associated with more neurological deficit and poor neurological prognosis. The present study also substantiate it; as there was statistical difference $(p=0.014)$ in neurological outcome between patients who had haemorrhage and those not having haemorrhage at the time of presentation. Similar findings had also been reported in other studies $[6,9,18,19,21,22,28-30]$.

Cord edema usually resolves with time and is associated with good neurological recovery. Significant $(\mathrm{p}<0.001)$

Table 5: Correlation matrix of MRI findings and ASIA score (Spearman's correlation test).

\begin{tabular}{|c|c|c|c|c|c|c|c|c|c|c|}
\hline & \multicolumn{9}{|c|}{ MRI findings } & \multirow[b]{2}{*}{$\begin{array}{l}\text { ASIA } \\
\text { Score }\end{array}$} \\
\hline & 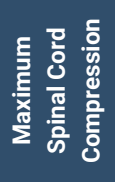 & 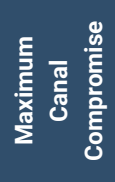 & 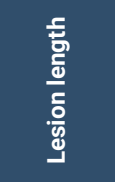 & 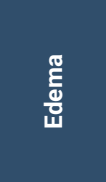 & 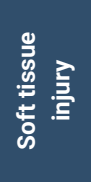 & $\begin{array}{l}\frac{\infty}{8} \\
\frac{0}{5} \\
\text { ちँ }\end{array}$ & 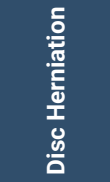 & 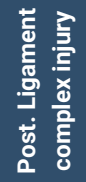 & 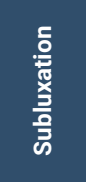 & \\
\hline $\begin{array}{c}\text { Initial } \\
\text { ASIA score }\end{array}$ & $-.661^{\star \star}$ & $-.703^{\star \star}$ & -.678 ** & -0.237 & -0.105 & $-.577 \star \star$ & $-0.420 *$ & -0.207 & -0.009 & 1.000 \\
\hline $\begin{array}{l}\text { ASIA score } \\
\text { at } 3 \text { months }\end{array}$ & $-0.780 \star \star$ & $-0.823^{\star \star}$ & $-0.730 \star \star$ & $-508 * \star$ & -0.127 & $-0.613^{\star \star}$ & $-0.575^{\star \star}$ & -0.278 & 0.000 & 1.000 \\
\hline $\begin{array}{l}\text { ASIA score } \\
\text { at } 6 \text { months }\end{array}$ & $-0.740 * \star$ & $-0.700 * *$ & $-0.591 * \star$ & $-0.607^{\star *}$ & -0.228 & $-0.683^{\star \star}$ & $-0.474^{* *}$ & -0.259 & 0.000 & 1.000 \\
\hline
\end{tabular}

Table 6: Agreement in neurological recovery according to ASIA score and MRI findings.

\begin{tabular}{|c|c|c|c|c|}
\hline \multirow{2}{*}{\multicolumn{2}{|c|}{ Neurological recovery by MRI findings }} & \multicolumn{2}{|c|}{ Neurological recovery by ASIA score } & \multirow{2}{*}{ Kappa Agreement } \\
\hline & & No & Yes & \\
\hline \multirow{2}{*}{ Spinal cord compression } & No & 0 & 0 & \multirow{2}{*}{$\begin{array}{l}K=0.000 \\
p=1.000\end{array}$} \\
\hline & Yes & 7 & 28 & \\
\hline \multirow{2}{*}{ Maximum canal compromise } & No & 1 & 0 & \multirow{2}{*}{$\begin{array}{l}\mathrm{K}=0.211 \\
\mathrm{p}=0.042\end{array}$} \\
\hline & Yes & 6 & 28 & \\
\hline \multirow{2}{*}{ Lesion length } & No & 3 & 8 & \multirow{2}{*}{$\begin{array}{l}K=0.118 \\
p=0.466\end{array}$} \\
\hline & Yes & 4 & 20 & \\
\hline \multirow{2}{*}{ Edema } & No & 3 & 5 & \multirow{2}{*}{$\begin{array}{l}K=0.237 \\
p=0.159\end{array}$} \\
\hline & Yes & 4 & 23 & \\
\hline \multirow{2}{*}{ Soft tissue injury } & No & 2 & 1 & \multirow{2}{*}{$\begin{array}{l}K=0.318 \\
p=0.035\end{array}$} \\
\hline & Yes & 5 & 27 & \\
\hline \multirow{2}{*}{ Stenosis } & No & 4 & 12 & \multirow{2}{*}{$\begin{array}{l}K=0.096 \\
p=0.497\end{array}$} \\
\hline & Yes & 3 & 16 & \\
\hline \multirow{2}{*}{ Disc herniation } & No & 5 & 15 & \multirow{2}{*}{$\begin{array}{l}K=0.105 \\
p=0.393\end{array}$} \\
\hline & Yes & 2 & 13 & \\
\hline \multirow{2}{*}{ Post. ligament complex injury } & No & 1 & 3 & \multirow{2}{*}{$\begin{array}{l}K=0.043 \\
p=0.791\end{array}$} \\
\hline & Yes & 6 & 25 & \\
\hline \multirow{2}{*}{ Subluxation } & No & 0 & 0 & \multirow{2}{*}{$\begin{array}{l}K=0.000 \\
p=1.000\end{array}$} \\
\hline & Yes & 7 & 28 & \\
\hline
\end{tabular}


neurological recovery was also noted in patients with resolving edema during follow up. Kulkarni et al. [6] and Rao et al. [22] observed in different studies patients with cord edema recovered significantly. Similar observations were found by Chandra et al. where signal changes with transient cord edema reverted to normal on follow up imaging, had a better outcome [5].

In the present study while comparing the patients with complete injury spinal injury (ASIA A), incomplete injury (ASIA $\mathrm{B}, \mathrm{C}, \mathrm{D}$ ), and no deficit (ASIA E) for qualitative MRI parameters; there was significant difference in haemorrhage $(p=0.021)$ and soft tissue injury $(p=0.011)$ parameters only. Takahashi et al. also correlated the degree of cord compression with recovery of neurological function [29]. Singh et al. reported that patients with cord swelling and stenosis showed a trend towards severe neurological deficit at presentation $(p=0.816)$ but post-operatively there was a significant improvement for edema ( $p=0.01)$ and spinal cord stenosis $(p=0.001)$ [30]. Miyanji et al. documented that patients with complete SCIs also had higher frequencies of hemorrhage $(p<.001)$, edema $(\mathrm{p}<0.001)$, cord swelling $(p=0.001)$, stenosis $(p=0.01)$, and STI $(p=0.001)$. Cord swelling $(p<.001)$ was correlated with baseline ASIA motor scores, while haemorrhage $(p<0.001)$ and cord swelling $(p=0.029)$ were predictive of the neurologic outcome at followup. Hemorrhage $(\mathrm{p}<0.001)$ and cord swelling $(\mathrm{p}=0.002)$ were correlated significantly with follow-up ASIA score when taking account, the baseline neurologic assessment [11].

\section{Quantitative MRI findings}

In present study, mean MSCC was found to be $(83.14 \% \pm 2.04)$ among subjects with complete injury initially whereas subjects with no deficit had mean MSCC to be (11.50\% \pm 0.71$)$. MCC was found to be $(88.43 \% \pm 2.15)$ among subjects with complete injury initially whereas subjects with no deficit had mean MCC to be $(14.50 \% \pm 2.12)$. There was statistically significant difference in MSCC $(p=0.002)$ and MCC $(p=0.002)$; when we compared the difference between these two parameters in patients with complete injury spinal injury (ASIA A), incomplete injury (ASIA B,C,D), and no deficit (ASIA E). Singh at al. reported that patients with complete injury had significantly more MSCC $(P<$ $0.001)$ and $\operatorname{MCC}(P<0.001)$ in comparison to incomplete injury as well as in comparison to neurologically healthy patients (MSCC $[P<0.001]$, MCC $[P<0.001][30]$.

Meves et al. found that patients with neurological deficit had greater canal compromise [21]. Similar results were observed by Miyanji, et al. [11] ( $p=.005)$ and Haar, et al. [13] ( $p=0.009)$ in their studies with more substantial MCC in complete SCI than patients with incomplete SCIs or those with no SCI, while correlated with baseline ASIA motor scores in cervical spine. Greater canal compromise is significantly associated with severity of neurological deficit and prognosis as documented in literature $[5-13,18-30]$.

The mean lesion length was found to be $(19.29 \mathrm{~mm} \pm 7.00)$ among subjects with complete injury initially whereas subjects with no deficit had mean lesion length to be zero as they didn't had any lesion at all. Singh et al. noticed $28 \%$ improvement in lesion length from $25.25 \pm 29.55 \mathrm{~mm}$ to $18.15 \pm 22.75$ in first 3months, further increment by $19 \%$ in next 3 months and by $16.4 \%$ in next 6 months (at 1 year) follow up. Lesion length decreased in all patients on each follow up and it was statistically significant $(p=0.001)$ [30]. Studies by Miyanji et al. [11] ( $p=0.005)$ and Haar, et al. [13] $(p=0.001)$ revealed more substantial lesion length with complete motor and sensory SCIs than patients with incomplete SCIs or no SCI in cervical spine. The length of lesion $(p=0.019)$ correlated with baseline neurology and was predictive $(p=0.011)$ of a poor neurological outcome.

\section{Correlation between MRI findings and ASIA score}

Correlation between MRI findings and ASIA score were obtained by Spearman's correlation test at different point of time and explained in Table 5. The statistically significant correlation of ASIA score with MRI findings was found to be with MCC (-0.703) followed by lesion length (-0.678), MSCC $(-0.661)$, stenosis $(-0.577)$ and disc herniation $(-0.420)$. The rest of MRI findings didn't have significant correlation with ASIA score at any point of time. However, decrease in edema significantly correlated with ASIA score at 3 and 6 months post injury. Extensive literature review did not reveal any study in English literature reporting agreement of neurological recovery according to ASIA scores and MRI findings at the time of start of present study in 2014. At the time of writing the article again literature search was done and we found one study by Matsushita et al. in 2017 in English literature reporting agreement of neurological recovery according to ASIA scores and MRI findings. They evaluated only the relationship between the vertical diameter of T2 high-intensity change in acute cervical spine cord injury, and observed a significant relationship 2-3 days after injury between the vertical diameter of T2 high-intensity area and the neurologic prognosis at discharge. There was correlation between intramedullary highintensity changed area (ISI) and ASIA motor score at admission and at discharge $(P<0.05)$, but the correlation coefficient was low (0.3766 at admission and 0.4240 at discharge) in patients admitted 0-1 day after injury; while in patients admitted 2-3 days after injury, there was a significant correlation between the ISI and ASIA motor score at admission and at discharge $(P<$ 0.05 ), and the correlation coefficient was very high (0.6840 at admission and 0.5293 at discharge) [31]. Present study is the first one to report relationship between multiple MRI findings and ASIA score over different point of time after discharge.

\section{Agreement between neurological recoveries diagnosed by ASIA score and MRI findings}

As shown in Table 6, statistically significant kappa agreement between neurological recovery diagnosed by ASIA score and MRI findings was found with maximum canal compromise $(\mathrm{k}=0.211)$ and soft tissue injury $(\mathrm{k}=0.318)$ only. We could not find in the literature any study reporting agreement between ASIA score and MRI features to predict neurological recovery for comparison purposes.

\section{Conclusions}

From the present study, it was observed that there is a significant correlation between MRI findings and ASIA score 
at different point of time post SCI. The statistically significant correlation was found to be with MCC $(-0.703)$ followed by lesion length (-0.678), MSCC $(-0.661)$, stenosis $(-0.577)$ and disc herniation $(-0.420)$ to prognosticate the neural recovery as determined by ASIA score. Furthermore, statistically significant kappa agreement between neurological recovery diagnosed by ASIA score and MRI findings was found with MCC ( $\mathrm{k}=0.211)$ and soft tissue injury $(\mathrm{k}=0.318)$. We suggest that serial neurologic examination and neuroimaging complement each other in prognosticating neurological recovery after acute traumatic SCI.

\section{References}

1. Nobunaga Al, Go BK, Karunas RB (1999) Recent demographic and injury trends in people served by the Model Spinal Cord Injury Care Systems. Arch Phys Med Rehabil 80: 1372-1382. Link: https://bit.ly/3dRdIFY

2. George LW, Wood II (2008) Fractures, dislocations and fracture-dislocations of the spine. In: Canale ST, Beaty JH, eds. Campbell's operative orthopaedics. 11th ed. Philadelphia. Mosby Elsevier 1761-1850. Link: https://bit.ly/2yCGswl

3. Sekhon LH, Fehlings MG (2001) Epidemiology, demographics, and pathophysiology of acute spinal cord injury. Spine 26: S2-12. Link: https://bit.ly/2Rb0F32

4. France JC, Bono CM, Vaccaro AR (2005) Initial radiographic evaluation of the spine after trauma: when, what, where, and how to image the acutely traumatized spine. J Orthop Trauma 19: 640-649. Link: https://bit.ly/2RfD5Cb

5. Chandra J, Sheerin F, De Heredia L (2012) MRI in acute and subacute posttraumatic spinal cord injury: pictorial review. Spinal Cord 50: 2-7. Link: https://bit.ly/2V3rCGZ

6. Kulkarni MV, McArdle CB, Kopanicky D (1987) Acute spinal cord injury: MR imaging at 1.5 T. Radiology 164: 837-843. Link: https://bit.ly/2XbNnqX

7. Morais DF, de Melo Neto JS, Meguins LC (2014) Clinical applicability of magnetic resonance imaging in acute spinal cord trauma. Eur Spine $\mathrm{J} 23$ : 1457-1463. Link: https://bit.ly/3dVQIAh

8. Kumar Y, Hayashi D (2016) Role of magnetic resonance imaging in acute spinal trauma: a pictorial review. BMC Musculoskelet Disord 17: 310. Link: https://bit.ly/2V4kPwN

9. Gupta R, Mittal P, Sandhu P (2014) Correlation of Qualitative and Quantitative MRI Parameters with Neurological Status: A Prospective Study on Patients with Spinal Trauma. J Clin Diag Res 8: 13-17. Link: https://bit.ly/3bRfiR5

10. Andreoli C, Colaiacomo MC, Beccaglia RM (2005) MRI in the acute phase of spinal cord traumatic lesions: relationship between MRI findings and neurological outcome. Radiol Med 110: 636-645. Link: https://bit.ly/2wgwCjc

11. Miyanji F, Furlan JC, Aarabi B, et al. (2007) Acute cervical traumatic spinal cord injury: MR imaging findings correlated with neurologic outcome- prospective study with 100 consecutive patients. Radiology 243: 820-827. Link: https://bit.ly/2JJGLYI

12. Parashari UC, Khanduri S, Bhadury S (2011) Diagnostic and prognostic role of MRI in spinal trauma, its comparison and correlation with clinical profile and neurological outcome, according to ASIA impairment scale. J Craniovertebr Junction Spine 2: 17-26. Link: https://bit.ly/3bVQBmA

13. Haar MT, Naidoo SM, Govender S (2011) Acute traumatic cervical spinal cord injuries: Correlating MRI findings with neurological outcome. SA orthop $\mathrm{J} 10$ : 35-41. Link: https://bit.ly/2x5yvQc
14. Steven K., Stephen B (2011) International standards for neurological classification of spinal cord injury (Revised 2011). J Spinal Cord Med 34: 547554

15. Farcy JP, Weidenbaum M, Glassman SD (1990) Sagittal index in management of thoracolumbar burst fractures. Spine 15: 958-965. Link: https://bit.ly/3dX9Yxb

16. Fehlings MG, Rao SC, Tator CH, Skaf G, Arnold P, et al (1999) The optimal radiologic method for assessing spinal canal compromise and cord compression in patients with cervical spinal cord injury. Part II: Results of a multicenter study. Spine 24: 605-613. Link: https://bit.ly/2UZPTOI

17. Chafetz RS, Vogel LC, Betz RR (2008) International standards for Neurologica Classification of Spinal Cord Injury: training effect on accurate classification. J Spinal Cord Med 31: 538-542. Link: https://bit.ly/39Me0F

18. Schaefer DM, Flanders A, Northrup BE (1989) Magnetic resonance imaging of acute cervical spine trauma. Correlation with severity of neurologic injury. Spine 14: 1090-1095. Link: https://bit.ly/3dUonu

19. Bondurant FJ, Cotler HB, Kulkarni MV (1990) Acute spinal cord injury a study using physical examination and magnetic resonance imaging. Spine 15: 161 168. Link: https://bit.ly/3c60Chd

20. Marciello MM, Flanders AE, Herbison GJ (1993) Magnetic resonance imaging related to neurologic outcome in cervical spinal cord injury. Arch Phys Med Rehabil 74: 940-946. Link: https://bit.ly/3dVhGbb

21. Shimada K, Tokioka T (1999) Sequential MR studies of cervical cord injury: Correlation with neurologic damage and clinical outcome. Spinal Cord 37: 410-415. Link: https://go.nature.com/2Xal2Qv

22. Rao KVLN, Saradhi MV, Purohit AK (2010) Factors affecting long term outcome in acute cervical cord injury. Indian Journal of Neurotrauma (IJNT) 7 149-156. Link: https://bit.ly/34fGarl

23. Meves R, Osmar A (2005) Correlation between neurologic deficit and spina canal compromise in 198 patients with thoracolumbar and lumbar fractures. Spine 30: 787-791. Link: https://bit.ly/3aNIvfv

24. Kang JD, Figgie MP, Boldmann HH (1994) Sagittal measurements of the cervical spine in subaxial fractures and dislocations: an analysis of two hundred and eighty-eight patients with and without neurological deficits. J Bone Joint Surg Am 76: 1617-1618. Link: https://bit.ly/2wg9aCE

25. Hayashi K, Yone K, Ito H (1995) MRI findings in patients with cervical spinal cord injury who do not show radiological evidence of a fracture or dislocation. Paraplegia 33: 212-215. Link: https://bit.ly/2X8FnHf

26. Ikata T, Iwasa K, Morimoto K (1989) Clinical considerations and biochemica basis of prognosis of cervical spinal cord injury. Spine 14: 1096-1101. Link: https://bit.ly/3dSimhH

27. Walker MD (1991) Acute spinal cord injury. N Engl J Med 324: 1885-1887 Link: https://bit.ly/39NDEcZ

28. Selden NR, Douglas j, Patel N (1999) Emergency magnetic resonance imaging of cervical spinal cord injuries: Clinical correlation and prognosis. Neurosurgery 44: 785-792. Link: https://bit.ly/2xVCkaw

29. Takahashi M, Izunaga $H$, Sato R (1993) Correlation of sequential MR imaging of injured spinal cord with. Prognosis. Radiat Med 1: 127-138. Link: https://bit.ly/3aSaSte

30. Singh R, Rohilla RK, Setia N (2015) A prospective study of neurologica outcome in relation to findings of imaging modalities in acute spinal cord injury. Asian J Neurol 10: 181-189. Link: https://bit.ly/2XctArb

31. Matsushita A, Maeda T, Mori E (2017) Can the acute magnetic resonance imaging features reflect neurologic prognosis in patients with cervical spinal cord injury? The Spine J 17: 1319-1324. Link: https://bit.ly/2wgxe8u

Copyright: () 2020 Singh R. This is an open-access article distributed under the terms of the Creative Commons Attribution License, which permits unrestricted use, distribution, and reproduction in any medium, provided the original author and source are credited.

Citation: Singh R, Meena VS, Sharma P, Kaur K, Svareen (2020) Prospective evaluation of relationship between MRI findings and ASIA score to predict neurological recovery in acute traumatic spinal cord injury. Int J Spine Res 2(1): 008-013. DOI: https://dx.doi.org/10.17352/ijsr.000008 